\title{
2029 Systemic sclerosis: detection of myocardial fibrosis by contrast-enhanced MRI
}

\author{
Kai Nassenstein*1, Frank Breuckmannn', Michael Huger ${ }^{2}$, Susanne Ladd ${ }^{1}$, \\ Peter Hunold ${ }^{1}$, Raimund Erbel ${ }^{1}$, Peter Altmeyer ${ }^{2}$, Alexander Kreuter ${ }^{2}$ and \\ Joerg Barkhausen ${ }^{1}$
}

Address: ${ }^{1}$ University Hospital Essen,, Essen, Germany and ${ }^{2}$ Ruhr University Bochum,, Bochum, Germany

* Corresponding author

from I Ith Annual SCMR Scientific Sessions

Los Angeles, CA, USA. I-3 February 2008

Published: 22 October 2008

Journal of Cardiovascular Magnetic Resonance 2008, I0(Suppl I):A298 doi:I0.II86/I532-429X-I0-SI-A298

This abstract is available from: http://jcmr-online.com/content/I0/SI/A298

(c) 2008 Nassenstein et al; licensee BioMed Central Ltd.

\section{Introduction}

Systemic sclerosis (SSc) represents a complex disorder of obscure etiology which affects the skin as well as various organs. Cardiac manifestations of SSc may result in pericardial disease, valvular disease, conduction system abnormalities, and arrhythmias; however, myocardial fibrosis is the hallmark with major impact on treatment and patients' prognosis.

\section{Purpose}

Thus, our study aimed to assess the potential of contrast enhanced cardiac MRI for early detection of cardiac involvement in patients with systemic sclerosis.

\section{Methods}

Our study included 35 patients (31 female, 4 male; mean age, $54 \pm 14$ years) with known systemic sclerosis and an age, sex and cardiovascular risk factors matched control group. Patients with known coronary artery disease (CAD) or a history of myocardial infarction were excluded from the study. All examinations were performed on a 1.5 T MR scanner (Magnetom Avanto, Siemens, Germany). The MRI protocol included Steady-State Free Precession cine sequences (TrueFISP, TR $3 \mathrm{~ms}$, TE $1.5 \mathrm{~ms}, \mathrm{FA} 60^{\circ}$ ) in long and short axis views for the assessment of myocardial function. Fat-suppressed T2-weighted turbo spin echo images (TR 2 heart beats, TE $49 \mathrm{~ms}, \mathrm{FA} 180^{\circ}$ ) in standard orientations were acquired for the assessment of myocardial edema. Additionally, an inversion-recovery fast low angle shot sequence (turboFLASH, TR $8 \mathrm{~ms}$, TE $4 \mathrm{~ms}$, TI $180-240 \mathrm{~ms}, \mathrm{FA} 20^{\circ}$ ) was applied in short and long axis views $10-15 \mathrm{~min}$ after injection of a $0.2 \mathrm{mmol} / \mathrm{kg} \mathrm{BW}$ of Gd-DTPA (Magnevist ${ }^{\mathrm{TM}}$, Schering AG, Berlin, Germany).

\section{Results}

Diagnostic image quality could be achieved in all but one patient. MRI detected cardiac abnormalities in $50 \%$ of our patients and in $24 \%$ of our control group. A reduced ejection fraction $(<55 \%)$ was observed in $7(21 \%)$ SSc patients, whereas no individual of the control group showed a reduced ejection fraction $(\mathrm{p}<0.05)$. Pericardial effusion was observed in $6(18 \%)$ SSc patients and in 1 $(3 \%)$ control $(\mathrm{p}>0.05)$. Ten $(26 \%)$ SSc patients and 3 $(12 \%)$ controls showed valve pathologies ( $p>0.05)$. Neither a SSc patient nor a control showed myocardial edema on T2-w images. Late enhancement of a non-ischemic pattern and not corresponding to a coronary territory was detected in $5(15 \%)$ SSc patients. In all instances, areas of poorly defined, patchy late enhancement (Figure 1a) and areas of well defined focal (Figure 1b) were detected in the mid-myocardial layer. Focal late enhancement was observed in the mid-myocardial layer of one control ( $3 \%$, $\mathrm{p}>0.05$ ).

\section{Conclusion}

The concept of myocardial late enhancement has been established for the assessment of myocardial viability. In chronic myocardial infarction, the accumulation of gado- 


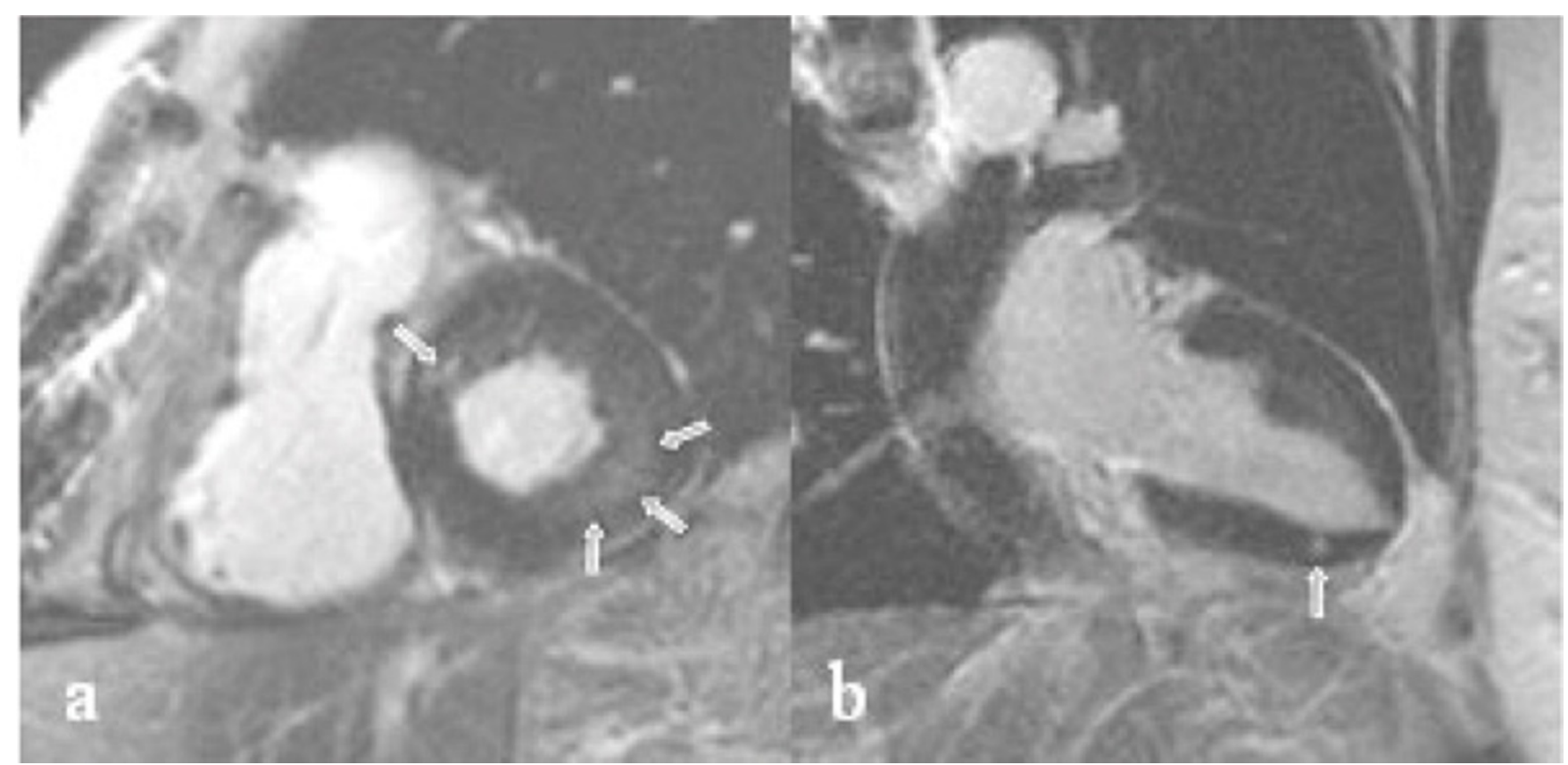

Figure I

linium-based contrast material reflects irreversible damage and scar formation. However, whereas LE is highly sensitive in characterizing myocardial scarring, it is not specific for ischemic damage since contrast agents generally accumulate in tissues with an increased interstitial space or areas with cell membrane damage. Thus, LE also occurs in myocardial areas of inflammation, edema, as well as fibrosis (Hunold, AJR 2005). Contrast-enhanced MRI must be considered as the imaging modality of choice for the detection of myocardial fibrosis in vivo. Our data show that late enhancement can be detected in $15 \%$ of SSc patients with no clinical evidence of myocardial involvement. Therefore, contrast-enhanced MRI seems to be well suited for screening of myocardial fibrosis, monitoring the progression and possibly evaluating therapeutic effects. However, long-term follow-up studies are mandatory to investigate the impact of late enhancement on patients' prognosis.
Publish with Biomed Central and every scientist can read your work free of charge

"BioMed Central will be the most significant development for disseminating the results of biomedical research in our lifetime. " Sir Paul Nurse, Cancer Research UK

Your research papers will be:

- available free of charge to the entire biomedical community

- peer reviewed and published immediately upon acceptance

- cited in PubMed and archived on PubMed Central

- yours - you keep the copyright
BioMedcentral 